\title{
Sistem Pakar Pemilihan Minat Program Studi Menggunakan Metode Forward Chaining
}

\author{
Muhammad Andre Syihab ${ }^{1}$, Septi Andryana ${ }^{2}$, Eri Mardiani ${ }^{3}$ \\ ${ }^{1,2,3}$ Universitas Nasional, Informatika, Fakultas Teknologi Komunikasi dan Informatika \\ Jl. Sawo Manila, Pejaten Ps. Minggu Jakarta 12520 \\ e-mail:*11 andreshihab@gmail.com, ${ }^{2}$ septi.andryana@ civitas.unas.ac.id, \\ erimardiani1@gmail.com
}

\begin{abstract}
Abstrak
Pemilihan program studi kuliah membuat pelajar menjadi bingung, karena belum memahami potensi diri sendiri sehingga membuatnya berfikir takut salah memilih jurusan program studi. Pada kenyataannya keputusan yang diambil dalam memilih program studi menjadi masalah, mulai dari mengikuti teman atau atas dasar paksaan orang tua. Pemilihan program studi benar-benar harus diperhatikan dan disesuaikan agar tidak menjadi penyesalan untuk kedepannya. Maka dari itu dibuatlah sistem pakar untuk memudahkan pelajar yang ingin memilih program studi kuliah. Metode yang digunakan adalah metode Forward Chaining untuk mengetahui solusi program studi yang harus diambil. Proses sistem pakar ini menerima pilihan-pilihan yang sudah tersedia dan sudah diisi oleh pelajar. Hasil dari sistem pakar ini memberikan solusi pemilihan program studi berdasarkan pendidikan sekolah yang diambil sebelumnya.
\end{abstract}

Kata kunci-Program Studi, Forward Chaining, Proses, Hasil

\begin{abstract}
The choice of a college study program makes students confused, because they do not understand their own potential so that it makes them think they are afraid to choose the wrong major in a study program. In fact, the decision made in choosing a study program becomes a problem, starting from following friends or on the basis of coercion from parents. The choice of study program must really be considered and adjusted so as not to be a regret in the future. Therefore an expert system was created to make it easier for students who want to choose a college study program. The method used is the Forward Chaining method to determine the study program solutions that must be taken. This expert system process accepts options that are already available and have been filled in by students. The results of this expert system provide a solution for selecting study programs based on previous school education.
\end{abstract}

Keywords — Study program, Forward Chaining, Process, Results

\section{PENDAHULUAN}

$\mathrm{P}$ erkembangan teknologi sangatlah pesat diera saat ini dan sangat mempengaruhi dunia pendidikan, mempermudah untuk mencari informasi mengenai pendidikan. Di era pandemi ini teknologi sangat membantu berjalannya kegiatan sekolah dari SD, SMP, SMA hingga kuliah. 
Pengambilan keputusan selalu ada dalam kehidupan manusia. Seperti pemilihan minat program studi kuliah terkadang menjadi masalah tersendiri. Seperti takut untuk memilih program studi dan bingung untuk memilihnya. Akibat terbesarnya akan mempengaruhi kegiatan perkuliahan kedepannya karena kesalahan memilih program studi. Biasanya mengikuti teman dan paksaan dari orang tua. Pengaruh mengikuti teman sangat besar karena sudah terbiasa bersama sehingga membuat diri menjadi yakin untuk memilih program studi yang sama. Paksaan dari orang tua juga sangat berpengaruh dalam pemilihan program studi, karena anak mendapat tekanan dari orang tua sehingga mau tidak mau mengikuti orang tua. Pembuatan aplikasi web ini akan mempermudah untuk memilih program studi berdasarkan potensi masingmasing.

Banyak sebagian calon mahasiswa bingung ataupun takut untuk memilih program studi yang ingin diambil, maka dari itu akan dibuat suatu sistem pakar untuk mengambil keputusan tersebut. Bagaimana mengimplementasikan sistem pakar pemilihan minat program studi menggunakan metode forward chaining agar memudahkan calon mahasiswa untuk memilih jurusan yang diinginkan. Untuk memudahkan pembuatan sistem pakar sehingga akan mempermudah untuk memilih jurusan. Seperti pengumpulan data survey mengenai setiap jurusan dan ciri-ciri setiap jurusan. Kelengkapan data sangat membantu pembuatan sistem pakar.

Pada penelitian terdahulu bahwa pemilihan program studi membuat para calon mahasiswa menjadi bingung atau takut salah memilih program studi. Maka dari itu pembuatan aplikasi berbasis web ini akan memudahkan calon mahasiswa untuk memilih program studi berdasarkan potensi diri masing-masing. Tidak mengikuti ajakan teman atau tekanan dari orang tua. Untuk menyelesaikan penelitian ini, sudah dilakukan beberapa kajian-kajian beberapa sumber, buku, jurnal, dan sebagainya. Sehingga jelas apa yang harus diteliti berdasarkan relevansi penelitian yang sama sebelumnya. Berdasarkan dari Penelitian sebelumnya metode yang digunakan adalah metode Forward Chaining. Sistem kerja aplikasi ini dengan cara menerima masukan seperti pengalaman yang dialami oleh siswa. Hasil dari aplikasi yaitu dapat memberikan petunjuk mata pelajaran yang cocok dengan bakat dan minat siswa. Dengan penerapan metode forward chaining yang diaplikasi pada sistem yang di atur dari rule jenis problem. Dari hasil keakuratan sebesar $89,29 \%$ maka dari itu sistem cukup baik untuk diterapkan [1].

Berdasarkan dari penelitian terdahulu MySql adalah bahasa permintaan yang terstruktur dan lebih mudah dipahami pengguna, karena MySql mempunyai beberapa aturan yang ditetapkan oleh asosiasi ANSI. MySql juga merupakan bahasa pemrograman yang digunakan untuk mengolah data dalam database [2].

Berdasarkan dari beberapa penelitian yang sudah dilakukan, maka penulis akan membuat sistem pakar berbasis web menggunakan metode forward chaining. Karena metode forward chaining sangat cocok untunk menganalisa beberapa data yang telah diperoleh dan diimplementasikan kedalam sistem. Sistem pakar yang akan dibuat untuk membantu siswa yang sudah lulus untuk memilih program studi yang diinginkan berdasarkan minat dan pengalaman siswa sendiri.

\section{METODE PENELITIAN}

\subsection{Tahapan Penelitian}

Untuk menyelesaikan perancangan aplikasi sistem, maka dari itu perancangannya sesuai dengan kerangka kinerja pada gambar 1. 


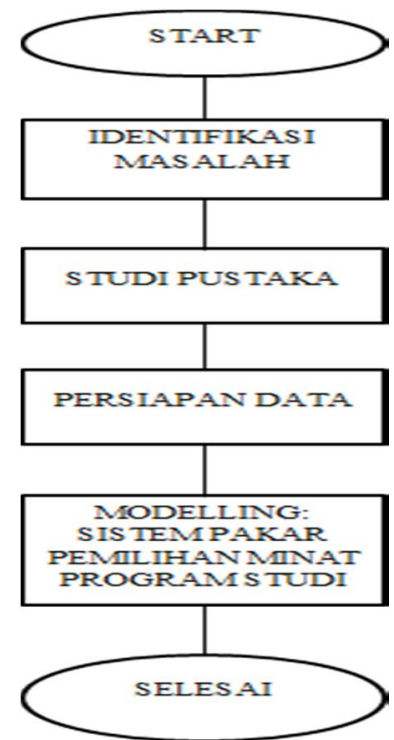

Gambar 1. Tahap-tahap Penelitian

Terdapat beberapa tahapan yang diperlukan untuk melaksanakan penelitian, yaitu:

a. Identifikasi Masalah

Menurut Sutrisno, identifikasi masalah merupakan suatu proses yang rumit, suatu proses yang sudah tersusun dari berbagai proses biologis dan psikologis. Ada dua hal yang sangat penting, yaitu pengamatan dan ingatan [3].

b. Studi Pustaka

Studi pustaka dilakukan untuk mengetahui apa saja yang dibutuhkan untuk melakukan sebuah penelitian, serta mengetahui batasan-batasan dari penelitian yang akan dilakukan.

c. Persiapan Data

Persiapan data merupakan pencarian data-data yang dibutuhkan, setelah itu dilakukan identifikasi data yang sudah diperoleh dan diimplementasikan kedalam sistem.

d. Modelling

Modelling, pada tahap ini pembuatan model atau bentuk rancangan dari sistem pakar yang akan dibuat.

\section{2 Metode Forward Chaining}

Metode Forward Chaining merupakan cara untuk mencari sebuah kesimpulan (solusi) berdasarkan dari fakta-fakta yang sudah ditetapkan. Penalaran diuji dari masing-masing fakta secara berurutan, penalaran dari masing-masing fakta dimulai dari informasi awal yang didapatkan hingga penyelesaian akhir yang diharapkan, maka dari itu proses-proses penalaran akan dilakukan secara berurutan [4].

Setelah dilakukan beberapa observasi dalam pengambilan data lalu disesuaikan dengan fakta-fakta yang sudah ditentukan. Fakta-fakta dicocokkan dengan bagian IF, setelah itu rule akan dicocokkan dengan fakta-fakta yang sudah ditentukan dan diimplementasikan dengan program sistem pakar dan disimpan di database untuk membantu pengolahan data [5]. Forward chaining menggunakan aturan menyesuaikan kondisi lalu dieksekusi. Pada metode ini sebuah data sangat berguna untuk memilih aturan yang akan dicocokkan dengan data atau dengan cara menambah data baru kedalam database untuk diproses oleh sistem agar ditemukan hasil sesuai yang diharapkan. 
Ada dua pendapat dari metode ini. Pertama dengan cara semua data diimplementasikan ke dalam sistem pakar. Kedua, memasukkan data yang penting-penting saja ke dalam sistem pakar. Teknik pertama lebih baik apabila sistem terhubung langsung dengan database. Teknik kedua lebih menghemat waktu dan biaya yang dibutuhkan dengan mengurangi dan memilih data yang diperlukan [6].

\section{HASIL DAN PEMBAHASAN}

\subsection{Implementasi Forward Chaining}

Forward chaining memilih rule mana yang akan dieksekusi berdasarkan pada pencocokan algoritma yang tujuan utamanya mencocokkan fakta-fakta dengan rule yang sudah ditentukan untuk mencari sebuah fakta baru dan kesimpulan sesuai yang diharapkan [7].

Program studi adalah suatu rencana belajar sebagai dasar pendidikan akademik berdasarkan suatu kurikulum yang sudah ditentukan. Ada beberapa program studi pada sistem pakar, dapat dilihat pada tabel 1 .

Tabel 1. Program Studi

\begin{tabular}{ccc}
\hline No & $\begin{array}{c}\text { Kode } \\
\text { Program } \\
\text { Studi }\end{array}$ & Program Studi \\
\hline 1 & S1 & Informatika \\
2 & S2 & Sistem Informasi \\
3 & S3 & Arsitektur \\
4 & S4 & Desain produk \\
5 & S5 & Manuajemen \\
6 & S6 & Kedokteran \\
7 & S7 & Bioteknologi \\
8 & S8 & Teologi \\
9 & S9 & Pendidikan Bahasa Inggris \\
10 & S10 \\
\hline
\end{tabular}

Berdasarkan klasifikasi program studi dan beberapa pernyataan yang sudah ditententukan, telah dibentuk tabel untuk pengelompokan pernyataan kedalam klasifikasi program studi. Pengelempokkan pernyataan pada tabel 2 .

Tabel 2. Pengelompokkan Pernyataan

\begin{tabular}{ccc}
\hline $\begin{array}{c}\text { Kode } \\
\text { Progra } \\
\text { m Studi }\end{array}$ & Program Studi & Rule Pernyataan \\
\hline S1 & Informatika & $1,2,3,4,5,6$ \\
S2 & Sistem Informasi & $7,8,9,10,11,12$ \\
S3 & Arsitektur & $13,14,15,16,17,18$ \\
S4 & Desain produk & $19,20,21,22,23,24$ \\
S5 & Akuntansi & $25,26,27,28,29$ \\
S6 & Manajemen & $30,31,32,33,34$ \\
S7 & Kedokteran & $35,36,37,38,39,40$ \\
S8 & Bioteknologi & $41,42,43,44,45,46$ \\
S9 & Teologi & $47,48,49,50,51,52$ \\
S10 & Pendidikan Bahasa Inggris & $53,54,55,56,57,58$, \\
\multicolumn{2}{c}{}
\end{tabular}


Proses padasistem pakar dengan cara mengajukan beberapa pertanyaan kepada pengguna, pengguna diharuskan menjawab agar sistem dapat berjalan dan meberikan kesimpulan dan solusi jurusan yang harus diambil [8]. Setiap rule memiliki beberapa pernyataan untuk dikelompokkan pada masing-masing program studi. Pernyataan yang sudah ditentukan akan dibaca oleh sistem untuk memberikan solusi pemilihan program studi yang tepat. Setiap pernyataan akan diuraikan pada gambar 2 .

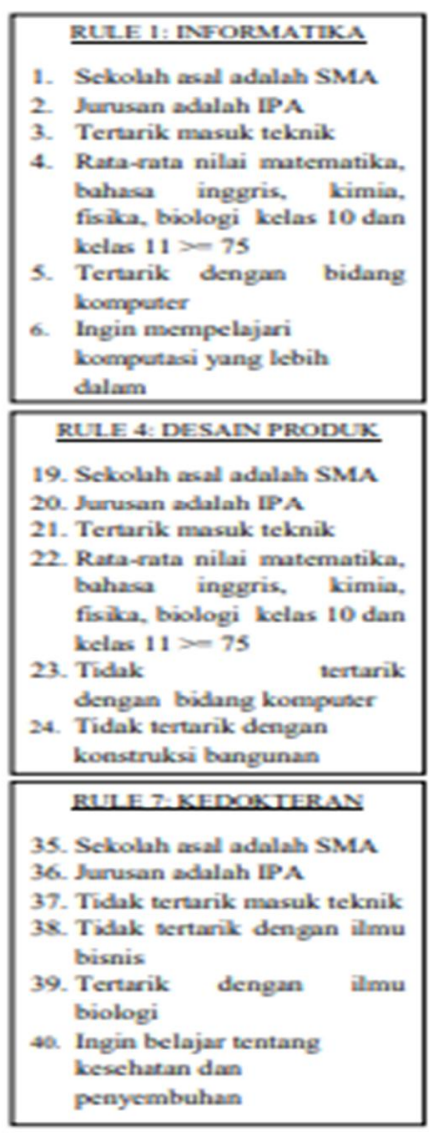

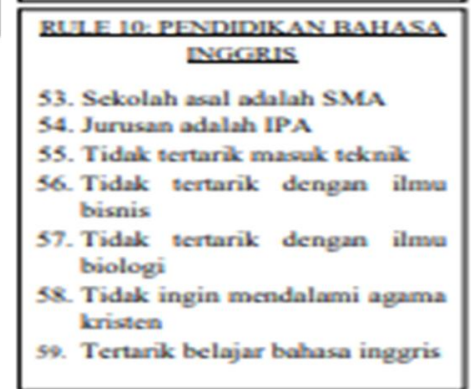

2. Sekolah asal SMA

. Jurusan adalah IPA

Tertarik masuk teknik

Rata-rata nilai matematika. bahasa ingeris, kimia, fisika biologe kelas 10 dan kelas 11 $>-75$

11. tertarik dengan bidang komputer

12. Tidak tertarik memapelajari komputasi lebih dalam

\begin{tabular}{|c|}
\hline RULE S: AKUNTANSI \\
\hline 25. Sekolah asal adalah SMA \\
\hline $\begin{array}{l}\text { 26. Jurusan adalah IPA } \\
\text { 27. Tidak tertarik masolk teknik }\end{array}$ \\
\hline 28. Tertarik dengan ilmu bisnis \\
\hline 29. Senang belajar tentang \\
\hline
\end{tabular}

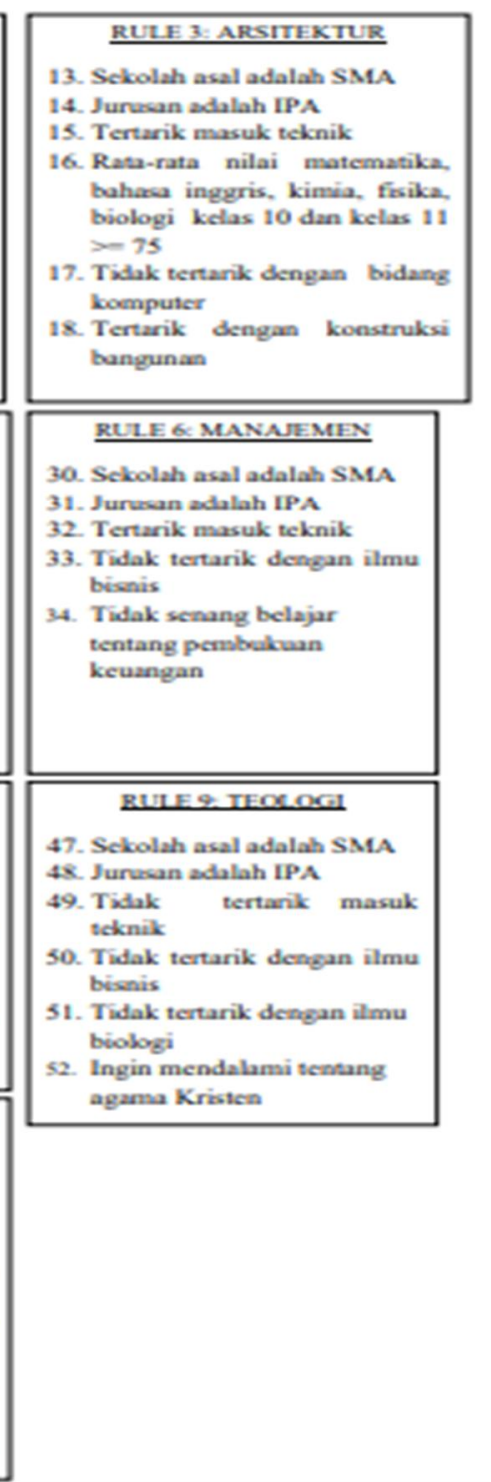

Gambar 2. Rule Pernyataan

\subsection{Use Case Diagram}

Pada dasarnya sistem pakar ini tidak memerlukan akses login untuk user, sehingga user dapat langsung menggunakan sistem pakar untuk mengetahui solusi penjurusan, use case diagram menghubungkan aktor dengan sistem [9]. Use case diagram dapat digunakan untuk mengetahui fungsi dan alur pada suatu sistem. Sistem pakar ini memiliki use case diagram yang di klasifikasikan menjadi 2, yaitu Admin dan User. Admin memiliki 3 akses, yaitu login, mengubah informasi untuk pertanyaan, dan logout. Sedangkan Admin memiliki 2 akses, yaitu 
melakukan tes pertanyaan dan melihat solusi penjurusan sementara. Use case dari masingmasing akses di gambarkan sebagai 3.

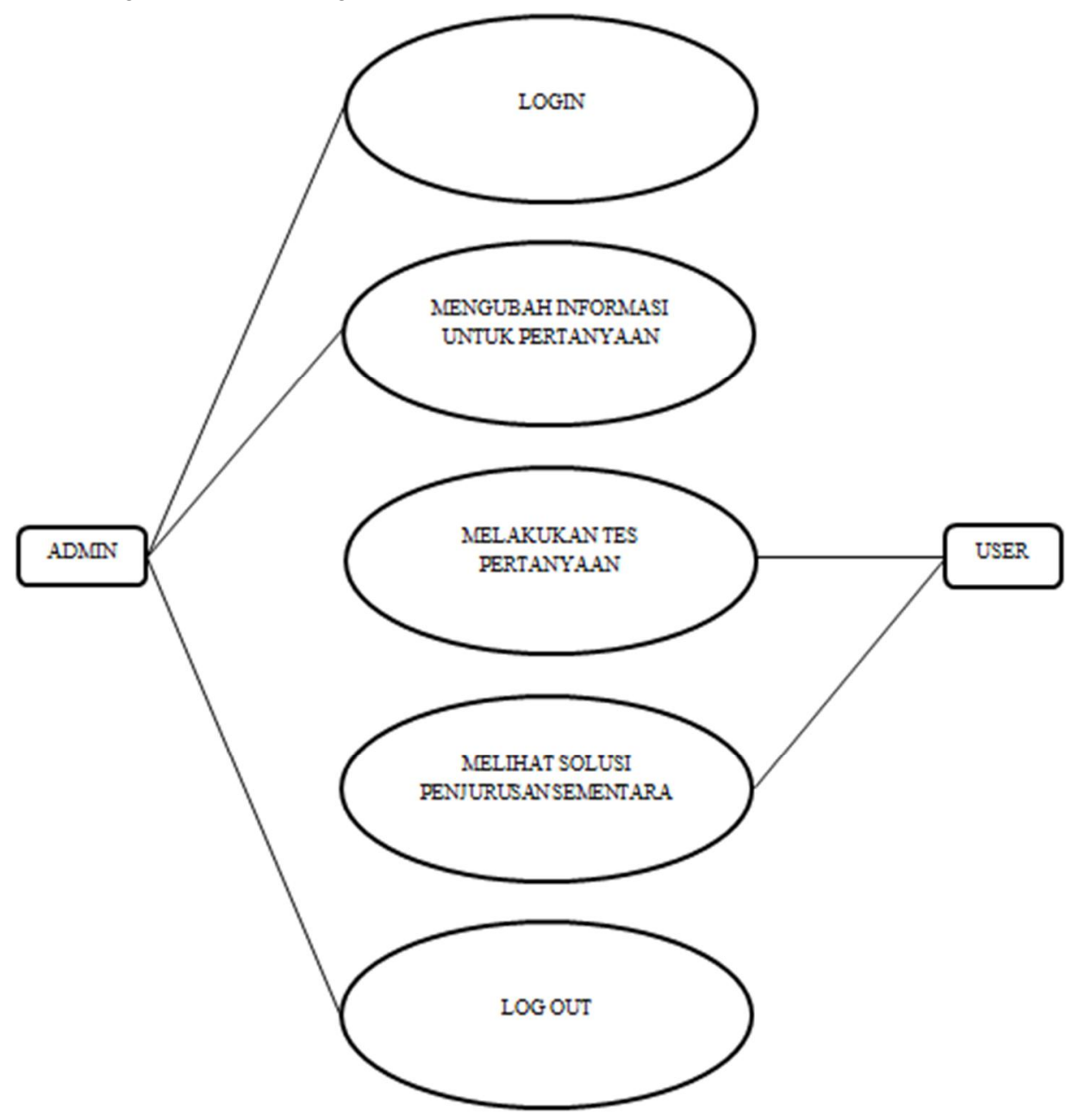

Gambar 3. Use Case Diagram Sistem Pemilihan Minat Program Studi

\subsection{Flowchart Sistem Pakar}

Flowchart merupakan bagan instruksi secara berurutan, menggambarkan suatu proses dengan proses lainnya menggunakan simbol-simbol [10]. Sistem pakar memiliki proses alur flowchart seperti pada gambar 4 . 


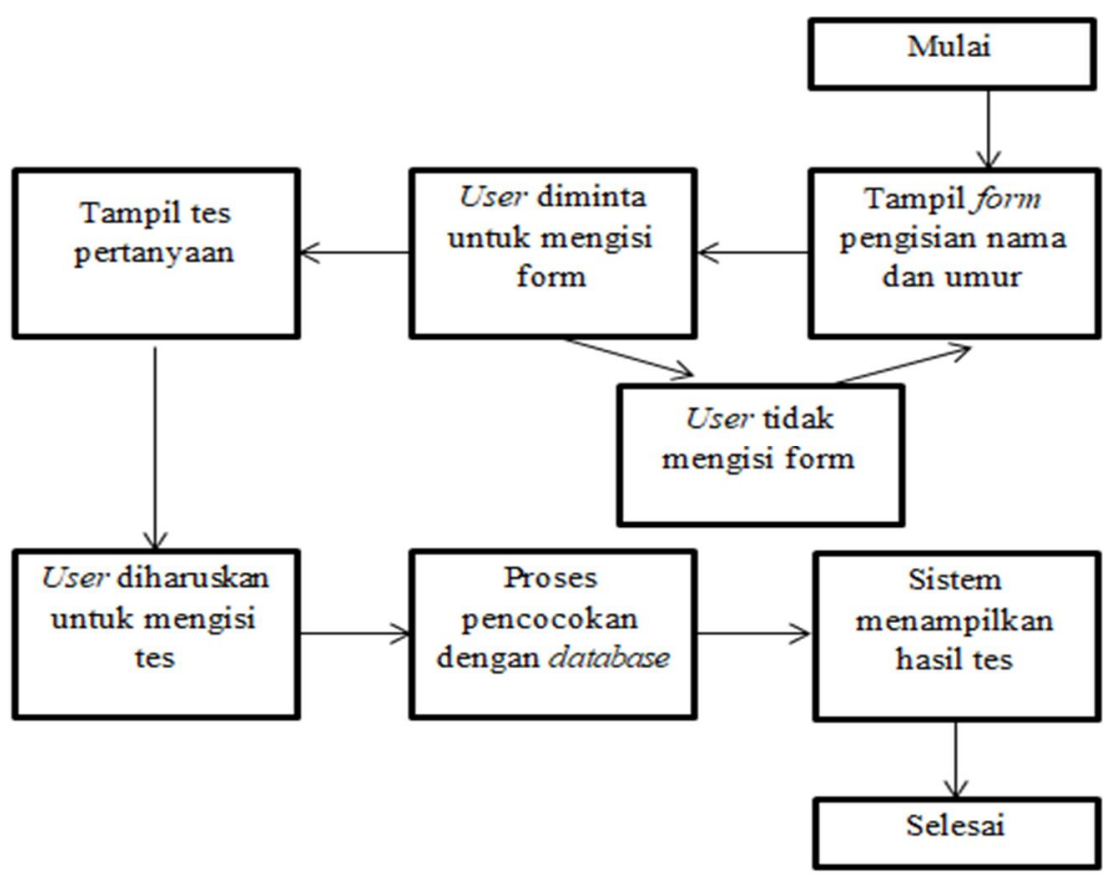

Gambar 4. Flowchart Sistem Pakar

a. Sistem menampilkan form nama dan umur untuk diisi oleh pengguna.

b. Pengguna diharuskan untuk mengisi tiap form yang ada.

c. Sistem memeriksa apakah setiap form sudah terisi. Jika tidak sistem tidak akan melanjutkan ke halaman tes pertanyaan.

d. Jika form sudah diisi sistem akan menampilkan halaman tes pertanyaan.

e. Sistem menampilkan halaman pertanyaan dan user diharuskan menjawab (ya atau tidak).

f. Sistem akan melakukan pencocokan jawaban user dengan database.

g. Sistem menampilkan hasil tes dan memberikan solusi.

\subsection{Implementasi Dan Design Sistem}

a. Tampilan Awal

Pada halaman ini terdapat sedikit informasi mengenai sistem pakar ini. Tedapat pilihan untuk login (hanya untuk admin) dan mulai (hanya untuk user). Tampilan dapat dilihat pada gambar 5.

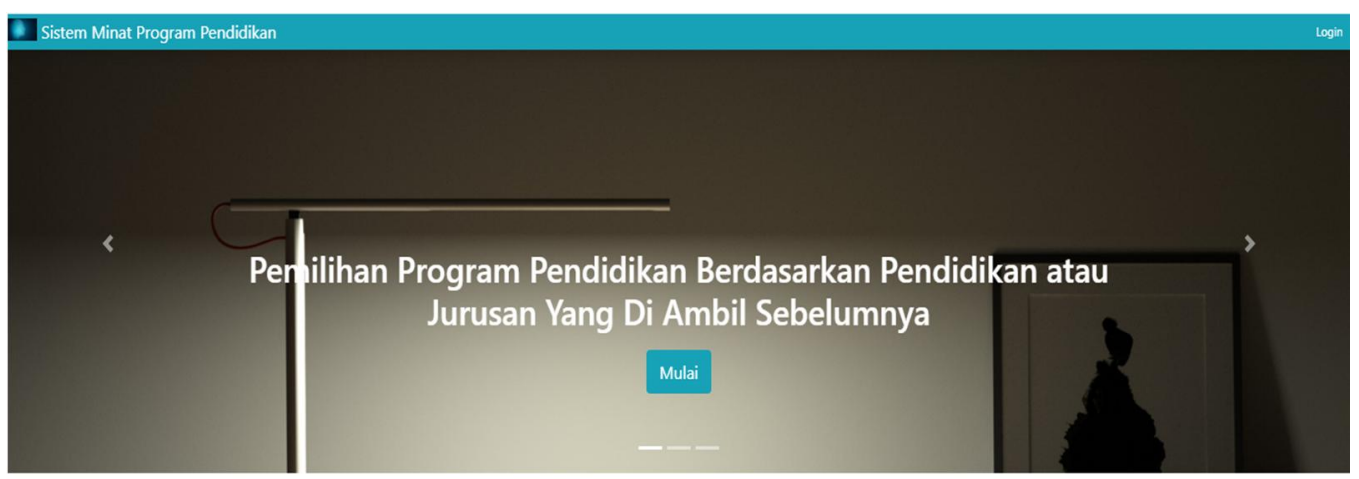

Gambar 5. Tampilan Awal 
b. Tampilan Isi Data Diri

Pada halaman ini user hanya perlu memasukan nama dan umur saja agar bisa mengakses web ini. Tampilan dapat dilihat pada gambar 6.

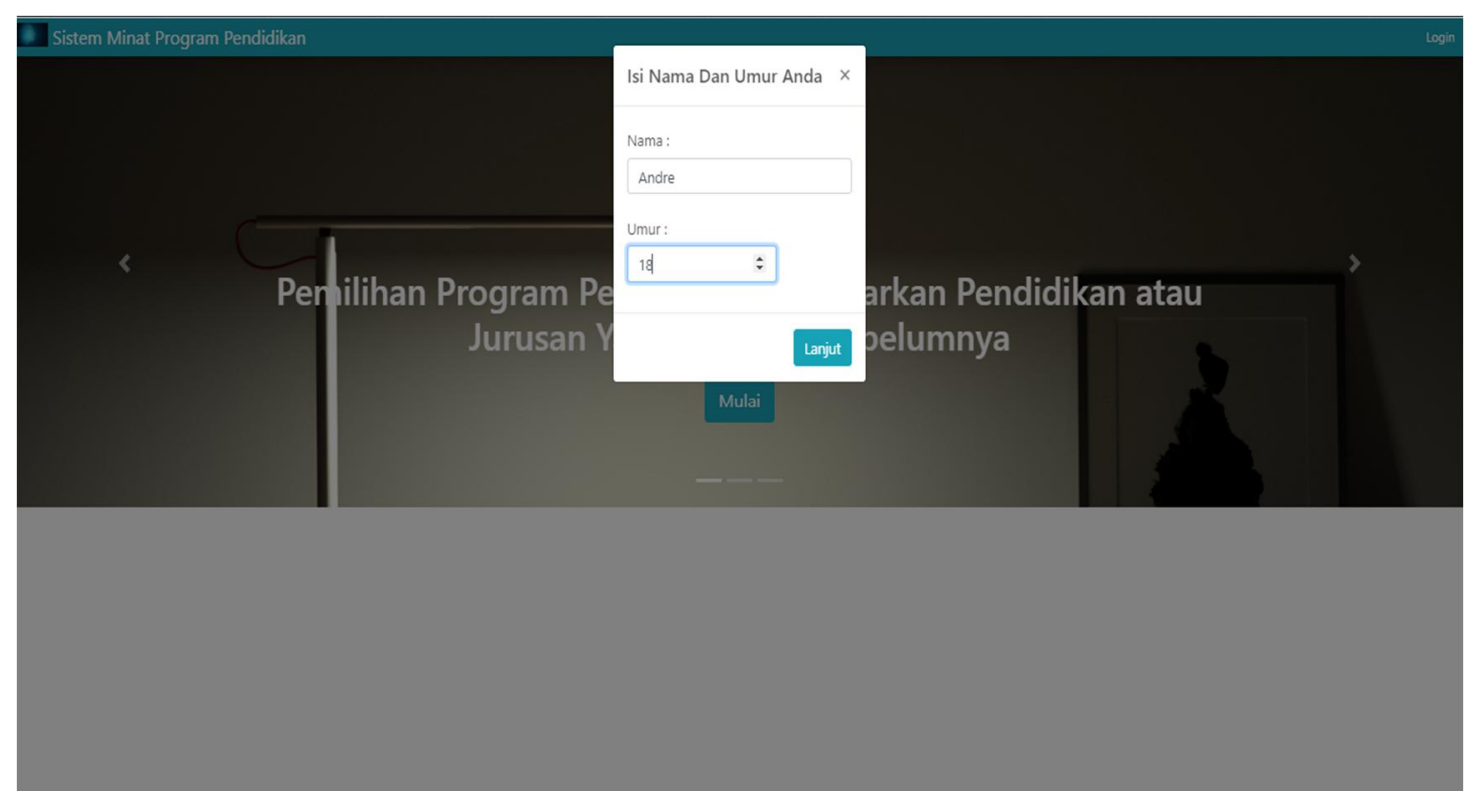

Gambar 6. Tampilan Isi Data Diri

c. Tampilan Tes Pertanyaan

Pada halaman ini user diminta untuk menjawab ('ya' atau 'tidak') agar sistem dapat memberikan solusi jurusan mana yang lebih baik untuk diambil. Terdapat beberapa pertanyaan, contohnya terdapat pada gambar 7 .

Sisiem Ninat Program Pendidikan

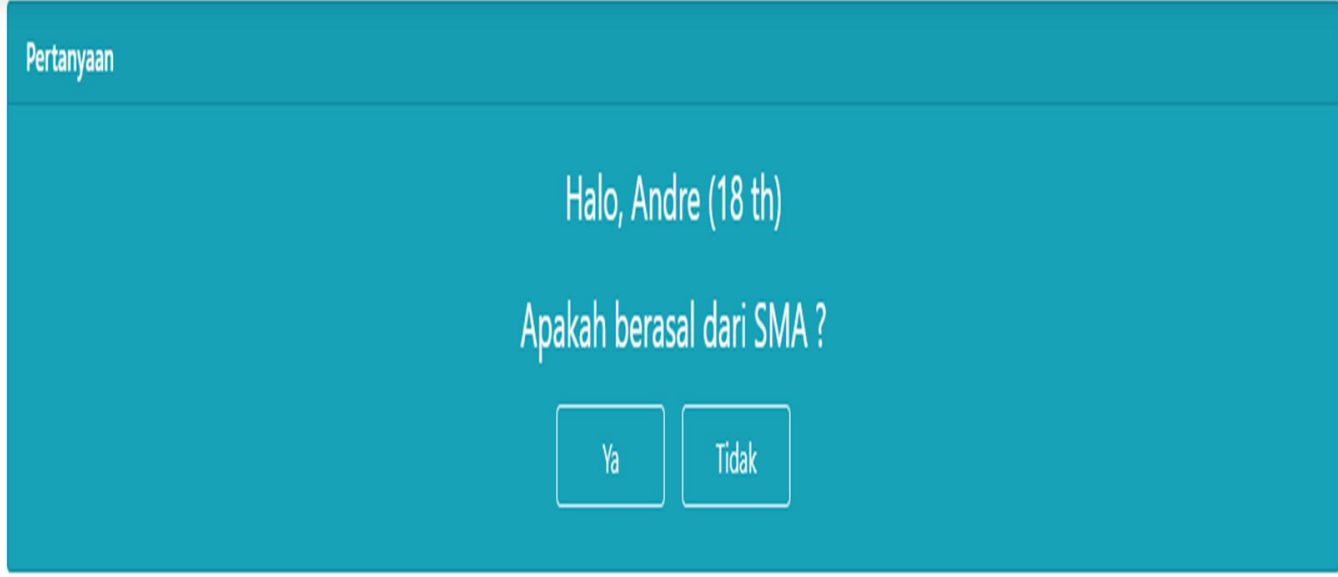

Gambar 7. Tampilan Tes Pertanyaan

d. Tampilan Hasil dan Solusi

Pada halaman ini terdapat hasil dari pengisian tes pertanyaan serta solusi jurusan yang seharusnya diambil. Hasil ini berdasarkan rule (aturan) forward chaining, tampilan dapat dilihat pada gambar 8 . 


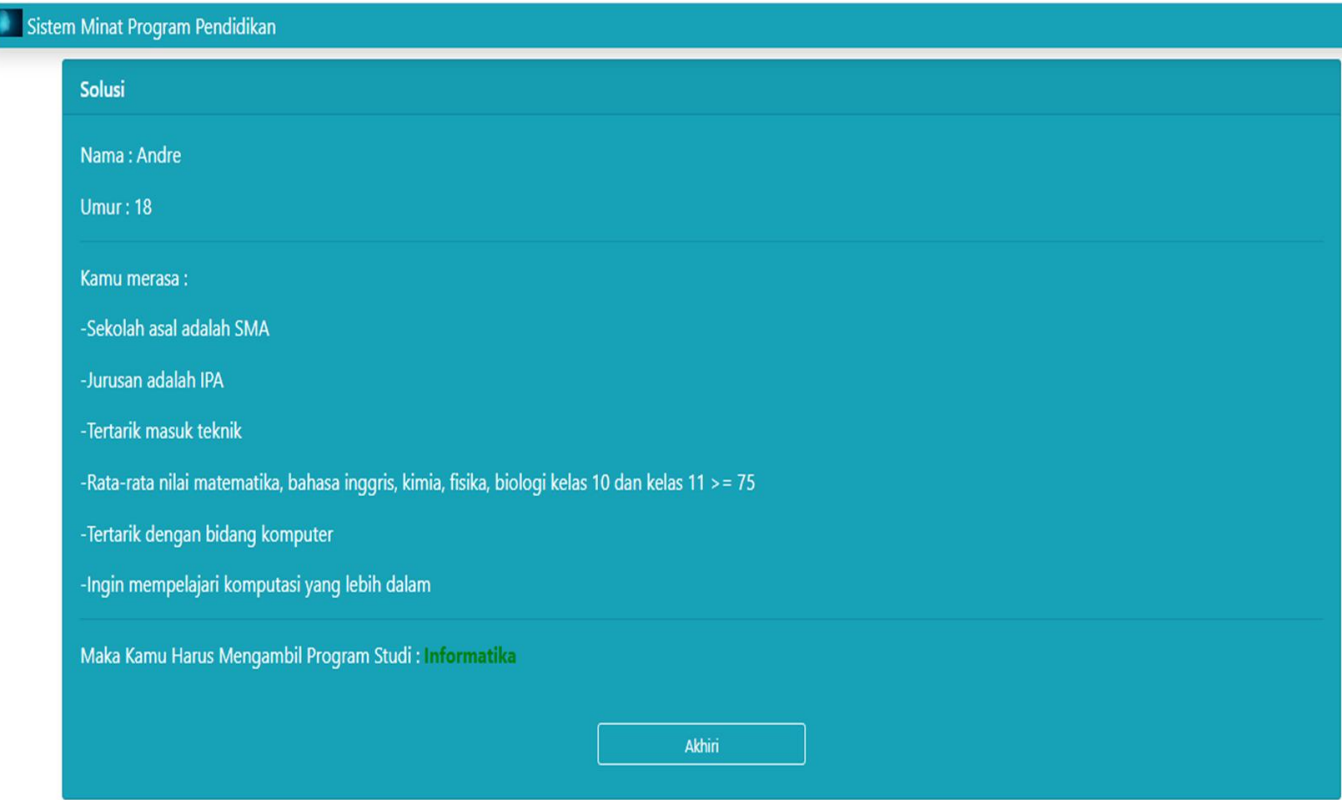

Gambar 8. Tampilan Hasil Dan Solusi

3.5 Hasil Pengujian Pada Sistem

Tabel 1. Pengujian Sistem

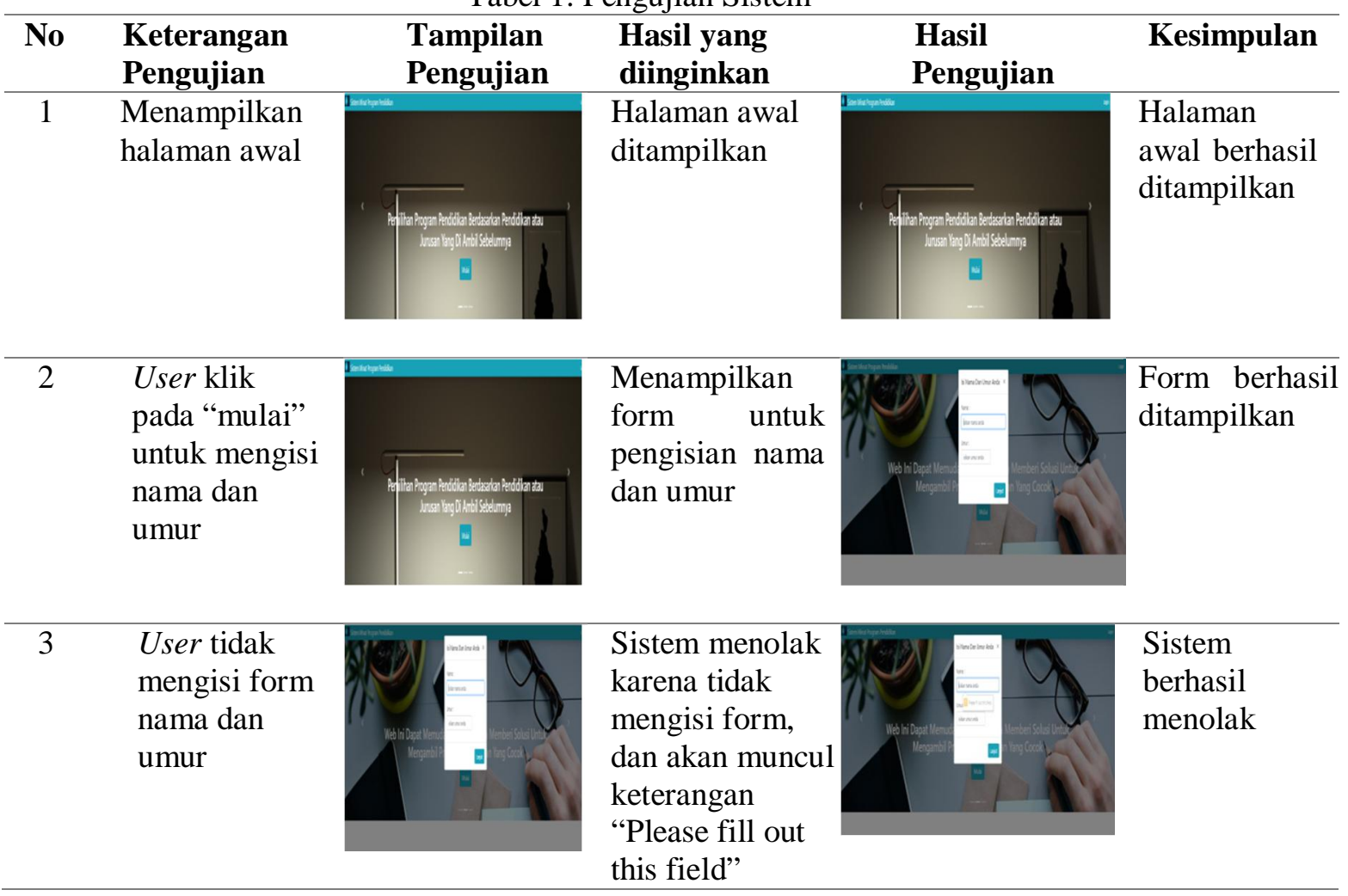




\begin{tabular}{llll}
\hline 4 & $\begin{array}{l}\text { User } \\
\text { mengisi } \\
\text { form nama } \\
\text { dan umur } \\
\text { setelah itu } \\
\text { klik "lanjut" }\end{array}$ & $\begin{array}{l}\text { Sistem akan } \\
\text { menampilkan } \\
\text { halaman tes } \\
\text { pertanyaan }\end{array}$ & $\begin{array}{l}\text { Sistem } \\
\text { berhasil } \\
\text { menampilkan } \\
\text { halaman tes }\end{array}$ \\
\hline 5 & $\begin{array}{l}\text { User } \\
\text { menjawab } \\
\text { beberapa tes } \\
\text { pertanyaan }\end{array}$ & $\begin{array}{l}\text { Sistem akan } \\
\text { berjalan dan } \\
\text { menampilkan } \\
\text { solusi dari } \\
\text { tes tersebut }\end{array}$ & $\begin{array}{l}\text { Sistem } \\
\text { berhasil } \\
\text { menampilkan } \\
\text { solusi } \\
\text { penjurusan }\end{array}$ \\
& & & \\
\end{tabular}

\section{KESIMPULAN}

Sistem pakar merupakan aplikasi yang digunakan untuk menyelesaikan masalah dan menemukan solusinya [11]. Berdasarkan penelitian yang sudah dilakukan, telah dibuat aplikasi sistem pakar menggunakan metode forward chaining untuk mempermudah pemilihan jurusan perguruan tinggi berdasarkan minat dan pendidikan sebelumnya. Aplikasi telah berjalan seperti yang diharapkan sesuai dengan rule dari metode forward chaining dan dapat memberikan solusi kepada pengguna. Diharapkan penelitian dan pembuatan aplikasi berbasis web ini dapat menambah informasi, serta dapat digunakan oleh masyarakat luas. Penggunaan aplikasi ini dapat membantu masyarakat yang ingin melanjutkan pendidikannya untuk memilih jurusan perguruan tinggi yang inginkan.

\section{SARAN}

Penelitian ini masih banyak kekurangan, mulai dari penulisan, penggunaan kata, dan penyusunan Diharapkan penelitian ini dapat menambah informasi bagi pembaca jurnal ini. Apabila ada penelitian lanjutan semoga diperbaiki lagi seperti fitur baru, design sistem dan user interface. Agar aplikasi sistem pakar lebih baik lagi dan dapat digunakan oleh masyarakat luas.

\section{DAFTAR PUSTAKA}

[1] Desi, Yuhandri. 2019, "Sistem Pakar Konseling Mata Pelajaran Pilihan UNBK Menggunakan Metode Forward Chaining," Jurnal Sistim Informasi dan Teknologi, Vol. 1, No. 3.

[2] Mardiani. E, Rahmansyah. N, Kurniawan. H, Sensuse. D. I, Jayanta, 2016, Kumpulan Latihan SQL, Elex Media Komputindo, Jakarta.

[3] Fatmasari, Adi. 2019 "Pemilihan dan Pengembangan Karier Berdasarkan Minat, Bakat dan Kepribadian Remaja Menggunakan Forward Chaining.” Jurnal IT., Vol. 7, No. 1 
[4] Kurniawan, Defit, Yunus. 2021, "Sistem Pakar dalam Mengidentifikasi Minat Vokasi Menggunakan Metode Certainty Factor dan Forward Chaining." Jurnal Sistim Informasi dan Teknologi., Vol. 3, No. 2.

[5] Ahda, Sari. 2020 "Sistem Pakar Penentuan Kualitas Garam di Desa Sedayulawas Kabupaten Lamongan Menggunakan Metode Forward Chaining." Jurnal Ilmiah Teknologi Informasi Asia., Vol. 14, No. 1.

[6] Supartini, Hindarto. 2016, "Sistem Pakar Berbasis Web Dengan Metode Forward Chaining Dalam Mendiagnosis Dini Penyakit Tuberkolosis di JawaTimur." Jurnal IT., Vol. 1, No. 3.

[7] Munaiseche, Kaparang, Rompas. 2018, “An Expert System for Diagnosing Eye Diseases using Forward Chaining Method.” Materials Science and Engineering.

[8] Pramesti, Arifudin, Sugiharti. "Expert System for Determination of Type Lenses Glasses Using Forward Chaining Method." Scientific journal of Informatics, Vol. 3, No. 2, (2016).

[9] Kurniawan. T. A. 2018, "Pemodelan Use Case (UML): Evaluasi Terhadap Beberapa Kesalahan Dalam Praktik." Jurnal Teknologi Informasi dan Ilmu Komputer (JTIK)., Vol. 5, No. 1.

[10] Hoki. L, Marvin. E. 2019, "Perancangan Sistem Pakar Diagnosa ISPA Dengan Metode Forward Chaining.” Jurnal Technology Informatics \& Computer System., Vol. 8, No. 1.

[11] Hidayat. A. H, Gumilang. G. 2017, "Sistem Pakar Diagnosis Penyakit Yang Disebabkan Oleh Rokok Dengan Metode Forward Chaining." Jurnal Teknik Informatika., Vol. 5, No. 2. 